\title{
Differences in Naloxone Prescribing by Patient Age, Ethnicity, and Clinic Location Among Patients at High-Risk of Opioid Overdose
}

\author{
David Kispert, $M D^{1,2}$, Jenny L. Carwile, $S C D, M P H^{7}$, Kristen B. Silvia, $M D^{3}$, \\ Elizabeth $B$. Eisenhardt, $\mathrm{MD}^{7}$, and Kinna Thakarar, $\mathrm{DO}, \mathrm{MPH}^{1,2,4,5}$ \\ 'Department of Internal Medicine, Maine Medical Center, Portland, ME, USA; ${ }^{2}$ Tufts University School of Medicine, Boston, MA, USA; ${ }^{3}$ Department \\ of Family Medicine, Maine Medical Center, Portland, ME, USA; ${ }^{4}$ Maine Medical Center Research Institute, Scarborough, ME, USA; ${ }^{I n t e r M e d}$ \\ Infectious Disease, Portland, ME, USA.
}

J Gen Intern Med 35(5): 1603-5

DOI: $10.1007 / \mathrm{s} 11606-019-05405-9$

(c) Society of General Internal Medicine 2019

\section{INTRODUCTION}

Between 2016 and 2017, opioid overdose deaths increased by $12 \%$ in the USA, with one third of deaths attributed to prescription opioids. ${ }^{1}$ In response, communities and health care providers have distributed naloxone, a safe and cost-effective reversal agent for opioid intoxication, to people who inject drugs and, increasingly, other patient populations considered high-risk for opioid overdose. In March 2016, the Centers for Disease Control and Prevention (CDC) released a category A recommendation that naloxone be considered for coprescription to adults at high-risk for opioid overdose, including those with a history of overdose, history of substance use disorder, high opioid dosage ( $\geq 50$ morphine mg equivalent/ day), or concurrent benzodiazepines. ${ }^{2}$ In a population of patients receiving care at outpatient internal medicine (IM) clinics following the release of these recommendations, we report adherence to $\mathrm{CDC}$ recommendations and investigate associations between patient characteristics, clinic location, and $\mathrm{CDC}$ criteria with naloxone prescription.

\section{METHODS}

We retrospectively collected data on adult ( $\geq 18$ years) patients who visited any of five outpatient IM clinics (Cumberland County, ME) between April 1, 2016, and December 31, 2018, and met $\geq 1 \mathrm{CDC}$ criterion for being high-risk for opioid overdose. ${ }^{2}$ We restricted substance use disorder to opioid use disorder (OUD) and history of overdose to history of opioid overdose. We abstracted data on patient demographics, clinic location, high-risk criteria, and naloxone prescription from an outpatient IM provider or upon hospital discharge from the

Received July 15, 2019

Accepted September 20, 2019

Published online October 17, 2019 electronic medical record (EMR). We excluded one patient with documented naloxone prescription before April 1, 2016.

We compared the prevalence of naloxone prescription during the study interval by patient demographics, clinic location ( $\geq$ or $<$ state median household income), and high-risk criteria. We calculated statistical significance between groups using chi-square or Fisher's exact tests.

All analyses were performed in SAS EG (version 7.15). The Maine Medical Center Institutional Review Board approved this study.

\section{RESULTS}

Over a 33-month period, 1385 adult IM clinic patients were considered high-risk for opioid overdose, and 85 (6.1\%) of whom were prescribed naloxone. The prevalence of naloxone prescription was higher for younger patients [e.g., 25-34 years $(14.8 \%)$ vs. $55-64$ years $(3.9 \%), p<0.0001]$, patients receiving care at a clinic in a lower-income community $[<$ state median household income $(8.4 \%)$ vs. $\geq$ state median household income (3.7\%), $p=0.0003$ ], and Hispanic patients [nonHispanic (5.6\%) vs. Hispanic (20\%), $p=0.01]$ (Table 1). We found similar results when we restricted to naloxone prescriptions received from outpatient IM providers (data not shown). Patients visited a clinic a median of 5 times (range 1-54) after meeting high-risk criteria. Patients with a history of OUD or who met $>1$ high-risk criterion were most likely to be prescribed naloxone (Fig. 1).

\section{DISCUSSION}

Despite frequent clinic visits, only $6 \%$ of clinic patients considered high-risk for opioid overdose received a naloxone prescription. More prescriptions were written for younger adults, Hispanics, patients receiving care from clinics in 
Table 1 Characteristics of 1385 Patients Receiving Care at Outpatient Internal Medicine Clinics Who Were Considered High-Risk for Opioid Overdose, by Whether They Received a Naloxone Prescription, Cumberland County, ME, April 2016-December 2018, N (\%)

\begin{tabular}{|c|c|c|c|}
\hline & \multicolumn{2}{|c|}{$\begin{array}{l}\text { Prescribed naloxone by an outpatient internal } \\
\text { medicine provider }\end{array}$} & \multirow[t]{2}{*}{$p$ value } \\
\hline & No $(N=1300)$ & Yes $(N=85)$ & \\
\hline \multicolumn{3}{|l|}{ Age } & \multirow[t]{7}{*}{$<0.001$} \\
\hline 18-24 years & $32(91.4)$ & $3(8.6)$ & \\
\hline $25-34$ years & $201(85.2)$ & $35(14.8)$ & \\
\hline $35-44$ years & $219(92.0)$ & $19(8.0)$ & \\
\hline $45-54$ years & $259(95.9)$ & $11(4.1)$ & \\
\hline 55-64 years & $270(96.1)$ & $11(3.9)$ & \\
\hline$\geq 65$ years $^{\dagger}$ & $319(98.2)$ & $6(1.9)$ & \\
\hline \multicolumn{3}{|l|}{ Sex } & \multirow[t]{3}{*}{0.41} \\
\hline Male & $598(93.3)$ & $43(6.7)$ & \\
\hline \multirow{2}{*}{\multicolumn{3}{|c|}{ Race }} & \\
\hline & & & \multirow[t]{4}{*}{0.63} \\
\hline White & $1239(96.9)$ & $80(6.1)$ & \\
\hline Black & $26(89.7)$ & $3(10.3)$ & \\
\hline Non-White & $28(93.3)$ & $2(6.7)$ & \\
\hline \multicolumn{3}{|l|}{ Ethnicity } & \multirow[t]{3}{*}{0.01} \\
\hline Non-Hispanic & $1281(94.1)$ & $81(6.0)$ & \\
\hline Hispanic & $16(80.0)$ & $4(20.0)$ & \\
\hline \multicolumn{3}{|l|}{ Insurance } & \multirow[t]{4}{*}{0.22} \\
\hline Medicare/Medicaid & $603(93.3)$ & $43(6.7)$ & \\
\hline Private & $337(95.7)$ & $15(4.3)$ & \\
\hline \multirow{2}{*}{\multicolumn{3}{|c|}{ Location of patient }} & \\
\hline & & & \multirow[t]{3}{*}{0.65} \\
\hline All metro & $983(93.6)$ & $67(6.4)$ & \\
\hline Small/isolated rural & 315 (94.6) & $18(5.4)$ & \\
\hline \multirow{3}{*}{$\begin{array}{l}\text { Economic characteristics of clinic location } \\
<\text { Median state household income } \\
\geq \text { Median state household income }\end{array}$} & & & \multirow[t]{3}{*}{$<0.001$} \\
\hline & $653(91.6)$ & $60(8.4)$ & \\
\hline & $647(96.3)$ & $25(3.7)$ & \\
\hline
\end{tabular}

Criteria were based on 2016 Centers for Disease Control and Prevention recommendations and include history of opioid overdose, history of opioid use disorder, high opioid dosage ( $\geq 50$ morphine mg equivalent (MME)/day), or concurrent benzodiazepine use

"Statistical significance calculated using chi-square or Fisher's exact test

${ }^{\dagger}$ Percentages do not sum to 100 due to rounding

*Urban and rural designations were based on 2010 Rural Urban Commuting Area (RUCA) codes, a census tract-based classification system: all metro (1, 1.1), large rural $(2,2.1,3,4,4.1,5,5.1,6)$, small rural $(7,7.1,7.2,8,8.1,8.2,9,10.1,10.2,10.3)$, and isolated rural (10). Missing data, race, $N=$ 7; ethnicity, $N=3$; insurance, $N=4$

lower-income communities, patients who met $\geq 1$ CDC criterion, and those with a history of OUD. While national opioid overdose deaths are highest among younger adults, ${ }^{1} \mathrm{CDC}$ recommendations are impartial to patient characteristics, ${ }^{1}$ in- cluding age, suggesting that provider opinion or bias may influence whether a naloxone prescription is offered. The association between age and naloxone prescription is consistent with some previous studies suggesting that older patients

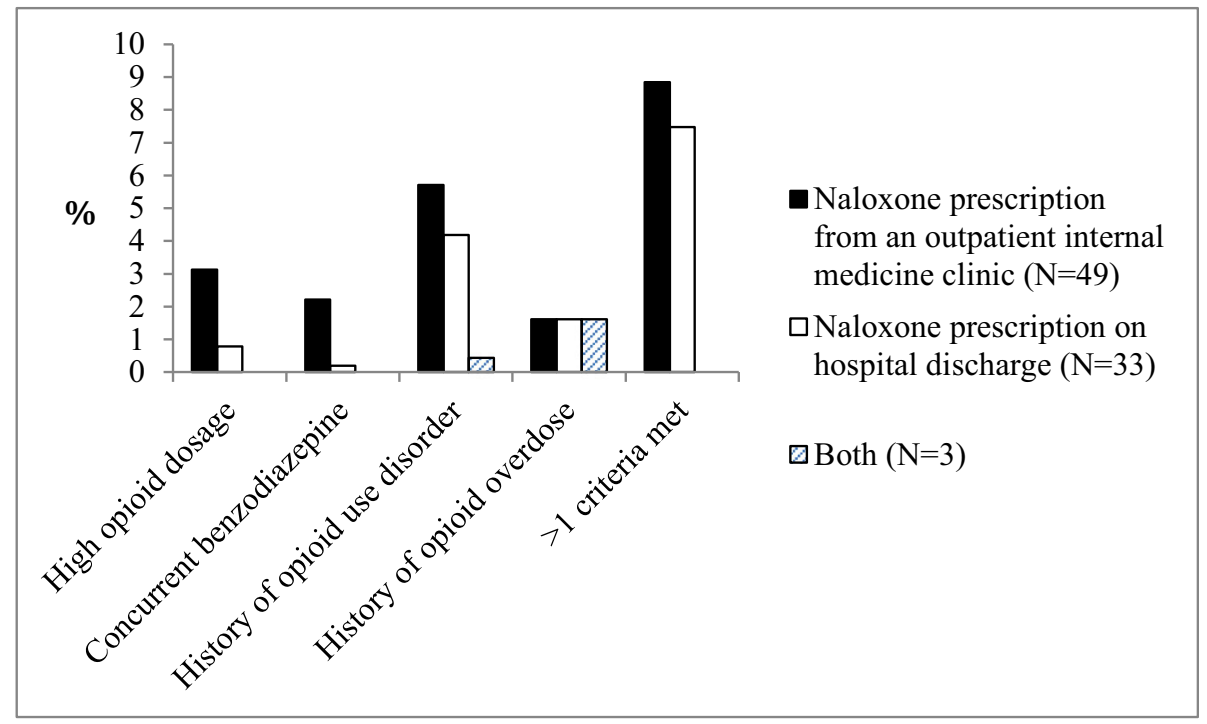

Figure 1 Criteria for being considered high-risk for opioid overdose (2016 Centers for Disease Control and Prevention recommendations), by source of naloxone prescription, among 1385 patients receiving care at outpatient internal medicine clinics in Cumberland County, ME, April 2016-December 2018. Among patients who met $>1$ criteria for being considered high-risk and were prescribed naloxone, the most common criteria for being considered high-risk were a history of opioid use disorder $(N=\mathbf{2 3}, 95.8 \%)$ and a history of opioid overdose $(N=18,75 \%)$. 
are less likely to be prescribed naloxone, ${ }^{3,4}$ but not others. ${ }^{5}$ To our knowledge, our study is the first to report that affluence of clinic location or patient ethnicity may influence naloxone prescription.

Limitations of our study include a single health system and inability to capture instances in which a naloxone prescription was refused. We lacked data on whether patients had previously obtained a naloxone kit or prescription from another source; however, this is unlikely to account for the plurality of this high-risk population who did not receive a naloxone prescription.

Primary care providers should use objective criteria, such as 2016 CDC recommendations, to determine the risk of opioid overdose and, for high-risk patients, prescribe naloxone. Future studies should investigate whether naloxone prescriptions vary by patient characteristics in other populations, to what degree this is influenced by provider bias, and which strategies for improving naloxone prescription (e.g., provider education, electronic triggers within the $\mathrm{EMR}^{6}$ ) are effective for reducing disparities in naloxone prescribing.

A previous version of this work was presented as a poster in November 2018 at the Association for Multidisciplinary Education and Research in Substance use and Addiction meeting.

Corresponding Author: Kinna Thakarar, DO, MPH; Department of Internal Medicine Maine Medical Center, 22 Bramhall St., Portland, ME 04102, USA (e-mail: kthakarar@mmc.org).

\section{Compliance with Ethical Standards:}

Conflict of Interest: The authors declare that they do not have a conflict of interest.

\section{REFERENCES}

1. Scholl L, Seth P, Kariisa M, Wilson N, Baldwin G. Drug and OpioidInvolved Overdose Deaths-United States, 2013-2017. MMWR Morb Mortal Wkly Rep. 2018;67(5152):1419-27. https://doi.org/10.15585/ mmwr.mm675152e1

2. Dowell D, Haegerich TM, Chou R. CDC Guideline for Prescribing Opioids for Chronic Pain-United States, 2016. MMWR Recomm Rep. 2016:65(1):1-49. https://doi.org/10.15585/mmwr.rr650lel

3. Coffin PO, Behar E, Rowe C, et al. Nonrandomized Intervention Study of Naloxone Coprescription for Primary Care Patients Receiving Long-Term Opioid Therapy for Pain. Ann Intern Med 2016;165(4):245-52. https://doi. org/10.7326/m15-2771

4. Wilson D, Berk J, Matson P, et al. A Cross-sectional Survey Using Clinical Vignettes to Examine Overdose Risk Assessment and Willingness to Prescribe Naloxone. J Gen Intern Med. 2018. https://doi.org/10.1007/ s11606-018-4733-y

5. Follman S, Arora VM, Lyttle C, Moore PQ, Pho MT. Naloxone Prescriptions Among Commercially Insured Individuals at High Risk of Opioid Overdose. JAMA Netw Open 2019;2(5):e193209. https://doi.org/10.1001/ jamanetworkopen.2019.3209

6. Behar E, Bagnulo R, Coffin PO. Acceptability and feasibility of naloxone prescribing in primary care settings: A systematic review. Prev Med 2018:114:79-87. https://doi.org/10.1016/j.ypmed.2018.06.005

Publisher's Note Springer Nature remains neutral with regard to jurisdictional claims in published maps and institutional affiliations. 